\title{
Identity Production on Social Media: The Narrative of Second- generation Youth of Sinhalese Sri Lankan Origin in New Zealand
}

\author{
WASANA SAMPATH HANDAPANGODA
}

\begin{abstract}
This qualitative study examines the identity claims of second-generation youth of Sri Lankan origin in New Zealand on social media, a social terrain that transcends the boundaries of traditional social worlds. Research participants' represented themselves online by three main strategies: visual (graphic), textual (narrative) and group. Participants simultaneously travelled back and forth between two virtual cultural identities, Kiwi and Sri Lankan, thus [re]constructing identity performances, in which "definition of the situation" played a key role. Their virtual identities represented only a snapshot of the self, where different versions of the self were performed and [re]produced, thus defying the essentialist or foundationalist notion of identity.
\end{abstract}

Keywords: Identity; Social media; Second-generation; Sri Lankan origin; Sinhalese; New Zealand

\section{Introduction}

New Zealand has always been a nation of immigrants. It was the last habitable landmass to be discovered, presumably in the $13^{\text {th }}$ century, by the ancestors of Māori, its indigenous peoples, with which its relatively short human history has begun. ${ }^{1}$ The 1840 Treaty of Waitangi formalized British settlement in New Zealand, and was followed by an inflow of European immigrants in the second half of the 19th century, and again in the postwar period in the 20th century, during which the immigration policies continued to favour European settlers. Ward and Masgoret note that "at the end of World War II, New Zealand had one of the most ethnically homogeneous societies of European settlement."2 However, in 1986 New Zealand's immigration policies underwent a major change from traditional to non-traditional sources, when the earlier focus on nationality and ethnic origin as the basis for admitting immigrants was replaced by an active recruitment of skilled and entrepreneurial immigrants regardless of ethnicity or nationality. As a result, today New Zealand hosts representatives from all the recognized countries in the world ${ }^{3}$ - that is, around 200 nation states - and is therefore becoming a multicultural society, as distinct from its previous state of biculturalism founded upon the Treaty of Waitangi. With immigrants from non-traditional sources steadily growing, today New Zealand can be characterized as a "permanently unfinished society."

New Zealand is home to a growing population of Sri Lankan origin. In 2013 there were over 9,500 Sri Lankan residents in New Zealand with the largest concentrations in Auckland and Wellington. Sri Lankan immigration to New Zealand has its roots in the colonial past. However, the largest inflows were observed after 1983 with the outbreak of the civil war, and the numbers increased after 1987, when the conflict worsened. ${ }^{5}$ Today New Zealand is home to several generations of Sri Lankan immigrants, both Sinhalese, the ethnic majority in Sri Lanka, and Tamil, an ethnic minority group.

For immigrants, settling down in a new society can be one of the most dynamic and complex processes in life. ${ }^{6}$ As Hamel writes, "Immigrants bring a wealth of culturally constructed ideologies with them into the target culture, where they are met by a different set of normative ways." "Survival in the host society with a new culture which is foreign poses the greatest challenge. Through the settling process, immigrants tend to undergo both personal and cultural changes, both invited and uninvited, that are enmeshed in a continuous process of 
identity production. The concept of "generation" is central to understanding these changes that immigrants undergo. Studies argue that it is specifically young immigrants who are deeply involved in personal and cultural changes and face pressure to cope with complex intergenerational tensions. ${ }^{8}$ This is because immigrant youth live within and between two cultures: the culture of origin inculcated in them by their parents, and the dominant host culture, the main acculturative context for them. In dealing with their intercultural situation, immigrant youth claim different identities, and the process of doing so is a "deeply contextual and theoretically and empirically complex enterprise." 9

This study looks at the identity claims of second-generation youth of Sinhalese Sri Lankan origin in New Zealand, a phenomenon that has received little attention in the field of immigration studies. It focuses on the identity claims made not in traditional social spheres, but rather in social media. As Youngs explains, social media is "the new social terrain with its own shapes and contours, shadows and openings, and threats and prospects ... [offering] new freedoms in terms of social and relational spaces and identities." 10 Social media is probably the most popular medium of communication among young people, and likely to consume a significant portion of their everyday life. It represents entirely new and unprecedented ways of social boundary drawing, self-expression, and social integration, and may have also eased assimilation pressures on young immigrants, all of which point to the importance of looking at identity claims in these virtual social spaces.

\section{Method}

The research approach adopted in this study is qualitative and grounded in the interpretive genre, on the basis that "the world is constructed through meaningful interpretations." 11 People construct a shared reality through interaction and dialogue. Research is a process of meaningful interaction guided and shaped by both the researcher's personal history, gender, social class, race and ethnicity, and by those with whom he or she interacts in order to collectively construct a meaningful reality. ${ }^{12}$ As researcher and subject communicate by sharing intended meanings, we construe and construct our social worlds through our words, symbols, and behaviours, and meanings emerge from the encounters "in the field."

The data was gathered over a period of nearly four months in 2014-15, applying two naturalistic methods: first, a single semi-structured, in-person interview was conducted with a total of 12 participants, seven males and five females, living in Wellington at the time of the study. Participants were recruited mainly through the identification of an initial informant, who referred me to potential participants who fitted the study requirements and in turn opened the possibilities for an expanding web of contacts, and, to a lesser extent, through my network of contacts within the Sri Lankan community in Wellington. Participants fitted the following criteria:

- $\quad$ Age 18-30 years, where the participants represented a fairly broad range of ages.

- Second-generation youth of Sinhalese origin living in Wellington. Secondgeneration is defined as having either been born in New Zealand to parents of Sri Lankan origin or having arrived in New Zealand with their Sri Lankan parents in their early teens, at the oldest. The subjects formed a "delineated population" that was likely to share similar cultural experiences in the host society. In this sense, second-generation is defined not as a cohort of people who were born in the same time period, but as a social or cultural construction through which immigrant experiences are reflected upon. For instance, according to King and Christou, the conceptualization of the second-generation is almost always correlated to its expected trajectory of assimilation into the host society. ${ }^{13}$

- $\quad$ Being a member of one or more social networking sites. 
Participants all identified as Sinhalese, and either had a university degree earned from a New Zealand university or were studying for a university degree in New Zealand, and a few of them were studying for their master's degrees in New Zealand while working, either full-time or part-time, in fields such as engineering, marketing and sales, accounting, human resource management, and information technology at the time of my fieldwork. They were spending on average an hour and twenty minutes on social media per day.

It is important to note that I conducted the interviews myself, belonging to the same ethnic community as the participants, thus an insider having fair knowledge of the target group and their culture, which facilitated a closer connection and deeper exploration of their ethnic minority experience in the host society. ${ }^{14}$ The interviews were conducted in English because the participants were both fully proficient and clearly more comfortable in communicating in English than in Sinhala, their native language. They spoke Sinhala, but were not as fluent as they were in English. For instance, two of the participants commented "I speak Sinhala, but I tend to mix the words here and there," and "I'm not fluent in Sinhala, but I can get by." The interviews were audio-recorded and later transcribed in their entirety by myself.

The second naturalistic method by which I gathered data was by conducting a virtual ethnography (i.e., fieldwork from my computer), a web search of the participants' personal social media profiles for the information and comments posted that were relevant for the purpose of my study. Participants were members of social networking sites, such as Facebook, Tumblr, Twitter, and Instagram, where they all had at least one personal social media account, mainly Facebook. The type of data that was collected online related to the participants' expression - explicit and implicit — of identity and feelings of belongingness. Their conception and expression of 'home' [us] and 'host' [them] through their posts on social media were scrutinized. In order to preserve anonymity of the participants, I used an alias online and remained 'unolbserved' in their virtual social spaces throughout the process of data collection. I refrained myself from any online dialogue (online chatting/posting) with the participants throughout and also avoided directly quoting any of their wall posts in the study. In citing the wall posts, I paraphrased them appropriately without altering or violating the content or meaning. In accessing social media accounts, in some cases, I was subject to "visibility rule"15 by the participants, where access to some accounts and data was unavailable or denied. My study was therefore carried out subject to this limitation of data. However, I could access at least one social media account of each participant, mainly Facebook. The main reason for the participants to be on social media was to keep in touch with friends and family in New Zealand and overseas including Sri Lanka. This study was approved by the human ethics committee of the institution I was affiliated with at the time of its initiation in New Zealand. Following its human ethics policy, I acquired the participants' written consent to participate in the study, to audio-record their in-person interviews, and to access their personal social media accounts subject to their own conditions and limitations, if they wished to specify any.

The two methods of data collection were complementary and corroboratory. The data were coded and analysed. Open coding identified and labelled the concepts and categories in raw data based on the properties or dimensions, which set the stage for axial coding. Axial coding helped me to see the connections between and among the categories and reassembled the categorized data. Axial coding was followed by selective coding through which the main storyline was identified as the basis for the integration of the main and sub-categories of data, thereby establishing and refining theoretical claims. ${ }^{16}$ In this study, however, I do not attempt to make claims to generalizations. 


\section{Identity in a Non-anonymous Online Setting: Study Focus}

Zhao et al. remind us that:

[i]dentity is an important part of the self-concept. Self-concept is the totality of a person's thoughts and feelings in reference to oneself as an object ... and identity is that part of the self "by which we are known to others...." The construction of identity is therefore a public process that involves both the "identity announcement" made by the individual claiming an identity and the "identity placement" made by others who endorse the claimed identity, and an identity is established when there is a "coincidence of placements and announcements." 17

In this placement-announcement dyad, the endorsement and thus the construction of identity is a social process, in which one's failure to conform to one's usual repertoire in that situational or relational context, can lead to disapproval from the relevant social group ${ }^{18}$ - that is, one can face a denouncement of identity. Therefore, people, for fear of being denounced or rejected make identity announcements that conform to the expectations of the particular audience that endorses their identity, which result in them simultaneously performing different versions of their identity and making varying identity claims that help them to minimize perceived placement-announcement conflicts. ${ }^{19}$

Referring to their study on a racially-diverse urban public university in the United States, Zhao et al. further note that in comparison with localized face-to-face interactions where identity is constructed under a unique set of constraints owing to physical embodiment, the Internet has set in motion major changes in these traditional conditions of identity production. The combination of disembodiment and anonymity creates a technologically mediated online setting in which a new mode of identity construction operates, which enables people to perform different personae, perhaps distinct from their "real life" identities. ${ }^{20}$ However, the virtual world is not entirely anonymous. Social media foster online relationships that are "nonanonymous"; these are offline-based online relationships and called here "anchored relationships," ${ }^{21}$ while the level of anchorage depends on the degree to which online partners are identifiable offline based on identifying information such as legal name, residential locality, and institutional membership. ${ }^{22}$ According to Morrill and Snow, anchored personal relationships are:

... relationships ... [that] have the dimension of warmth, rapport, [sense of belonging,] and intimacy normally connected with primary relationships yet occur within a secondary setting and have some aspects of secondary relationships. ${ }^{23}$

The concept of anchored relationships discussed here refers to individuals who are nonanonymous both online and offline. Identity production in such an online setting has not been adequately explored, where non-anonymity limits individuals' freedom of identity claims.

\section{Results}

Social media, as a digital platform, is unique in allowing participants to present themselves in a multiplicity of ways. Participants displayed photos and videos in their online albums, listed friends - mostly Sri Lankan - and social circles, posted messages, comments and pieces of writing, and talked about their personal interests and experiences online. In their online selfpresentation, the participants employed three main strategies: visual (graphic), textual (narrative), and group, through which they made both explicit and implicit statements of identity.

Visual or graphic modes of self-presentation involved the participants' display of photos on their social media accounts. These photographs were mainly their solo pictures and, less often, photographs with friends and family and of the places they have travelled with captions 
and/or comments posted underneath. Most photographs, including their profile pictures, were "carefully choreographed," 24 and presented the participants as friendly, outgoing, cool, and happy, an aspect of self-presentation that was more Kiwi or "Western" than Sri Lankan, and put up a mediated "public display" 25 of social desirability and acceptance. These selfpresentations were "playful" and deliberate and constructed exhibitionist performances of identity. ${ }^{26}$ According to Ferguson, happiness might be viewed as the most general expression of value in Western society. ${ }^{27}$ Happiness is a cultural construct, and in modern Western societies, individual happiness is generally construed as a highly desirable emotional state achieved by personal goal attainment and high self-efficacy ${ }^{28}$ - that is, by "success." Success, and thus happiness, are construed as goals for personal and individual pursuit, according to modern Western capitalist social practices. In capitalist Western societies, the notions of individual liberties and personal rights are therefore more salient and present a demand for a universal pursuit of happiness. ${ }^{29}$ In this sense, New Zealand is a capitalist "Western" society in so far as New Zealanders value personal freedom and the individual's right to success. The participants' visual modes of self-presentation as "happy" are predicated on these capitalist ideas of success, and thus the behavior of the participants conforms to Western ideas of happiness.

In terms of accessibility, most participants were willing to let outsiders see their photo albums and left everything open to the public, while some partly blocked access and maintained privacy - accessible privacy - for themselves and their friends. Some posted photographs of their holidays in Sri Lanka with family and friends living in Sri Lanka with whom they kept in touch through social media, and also of landscape and culture: as one female participant commented "When I go to Sri Lanka, I always post pictures showing off, you know the culture and whatnot, the food and everything." Such behaviour demonstrates the participants' "emotional intensity, intimacy and engagement" 30 in presenting themselves as Sri Lankan and thus their nationalist pride. They invested relatively higher levels of "social energy" 31 in their virtual ties with Sri Lanka and Sri Lankans. Participants also posted pictures of their life in New Zealand, such as the places they've travelled in New Zealand and social events and gatherings, through which they showed off their free-spirited and care-free personality. In these group photographs most participants presented themselves largely in the context of Sri Lankan friends and family members, which carried implications for their ethnic/cultural identity; they served as conceivable visual markers of their identification with Sri Lanka. As well, the participants did visually interact and post with non-Sri Lankans, including Kiwis and other Asians online. However, these online presentations and interactions with non-Sri Lankans did not carry implications for their ethnic and/or cultural identity; ethnicity was neither established nor alluded to in their visual interactions with non-Sri Lankans on social media.

In terms of visual modes, the participants exhibited a selective self-presentation, carefully choosing both the aspects of self to be presented and the audience to which self is presented, while claiming unique individual identities as well as collective cultural identities that they shared with offline-based online friends. As part of the rituals of cyber culture, visual modes functioned as codes and signs through which they constructed identity performances, which were both alternated (and "alterable") and mediated (and "mediatable").

Textual or narrative self-presentation primarily constituted the participants' comments on friends' uploads, sharing information such as articles and news pieces, and occasional posts on self and personal experiences. However, most participants remained less active and involved in terms of their textual posts on social media. This was because they were cautious of attracting negative attention through their textual posts, an awareness that spoke to their continued attempt to depict a self that was socially agreeable and desirable on social media. The following was expressed by one participant, a 24 year old female who has been living in New Zealand 
for nearly 20 years, regarding her textual posts: “Oh! god no. I don't usually because I find that it can start conflict. I try to stay away. I don't post stuff and I don't comment either. I don't like to get into debate." 32 However, through the little they posted the participants made both explicit and implicit ethnic or cultural identity statements. Their textual posts thus evidenced complex considerations of "the politics of narrative." 33 According to Pio, for immigrants, ethnic identity is of considerable importance particularly when they are a minority in the host society. Pio defines ethnic identity as "an individual's sense of self in terms of membership in a particular group, with value and emotional significance attached to that membership." 34 It is the sense of pride and attachment one experiences as being part of one's cultural group. One participant, a 25 year old female born in New Zealand, shared her personal experience, thoughts, and feelings, on her social media account, which carried implicit statements of her conflicting cultural attachments:

Post (1): Expressed feeling poorly as a Kiwi because she had missed seeing a celebrated work of art, which has been argued to evoke a feeling of patriotic duty among New Zealanders (Kiwis).

Post (2): Conveyed her good wishes for a peaceful future for \#Sri Lanka.

Post (3): Expressed a strong desire to [re]affirm her identity as "Sri Lankan" resulting from a rather unpleasant experience that she had encountered in the host society concerning her ethnic/cultural identity.

Post (4): Stated her explicit support for equality and the right to gender expression. ${ }^{35}$

The following were extracted from my interview with a 28 year old male who has been living in New Zealand since the age of three:

I'm quite careful about what I post and how I post and to whom I post. If I post to everyone what I'd post to a few people, then I'd get a lot of negative comments. I tailor my comments.

An alias or many aliases for people to avoid social stigmatization [on social media], to pursue interests that they want to pursue, say homosexuality. In Sri Lanka homosexuality is quite a stigma and can be very hard to express without having an anonymous alias online. Just things like that. People should have a choice. Should have the alternative of having an alias as well. ${ }^{36}$

And these comments are from a 26 year old female who has been born in New Zealand:

I don't always post Sri Lankan stuff, but I like to. I like to show off about Sri Lanka to people who don't know about it. So, probably that's why I do not post on Facebook because it's mostly Sri Lankan, but on other things [Tumblr, Twitter], so that random people might see. I do small acts of tourism. I like posting things on my blog about Sri Lanka. People would know what's going on there. Some people don't know Sri Lanka, or know them as Indians. ${ }^{37}$

In terms of textual self-presentation, the participants simultaneously travelled back and forth between two cultural identities: New Zealand or Kiwi (country of residence) and Sri Lankan (country of origin). Having lived in New Zealand their entire or most of their lives with exclusively or primarily New Zealand education, a major acculturative context for them, their fluency in English language facilitated effective connection with the host society and a sense of belongingness to it. Referring to previous studies Hwang and He note that immigrants' successful adaptation is possible only when they are able to communicate successfully with the host environment. ${ }^{38}$ The topics some participants engaged in online were rather broad and worldly ranging from elections in New Zealand to Taliban attacks in Afghanistan to more 
sparkling topics such as annual Grammy Awards, on which they were well-informed and upto-date. More importantly, a few made explicit posts supporting culturally-sensitive social realities, such as gender equality, homosexuality, and same-sex marriage. In Sri Lankan society, social phenomena such as homosexuality and same-sex romance are considered a "gross indecency," and remain largely disapproved by social custom to date. Through textual posts that supported and approved such social phenomena which are tabooed in their society of origin, Sri Lanka, they crossed cultural boundaries, "Othering" the normative ways of their country of origin. In doing so, they implicitly identified themselves with the norms and values of their host society, New Zealand, and thereby created a sense of "us" and belonging to New Zealand society.

At the same time, a few participants expressed criticism, though perhaps subtle, indirect and nuanced, of the values in the host society. For instance, one female participant posted that she wants to fight racial discrimination and protect human rights for all. Interestingly, she was rather evasive and discreet in her criticism, refraining from openly directing it at New Zealand society, but instead made innuendos. She also used a rather "soft language," such as phrases like "wanna make" and "cute stuff," to deliver her message, which toned down her criticism (or concealed reality) and maintained a sense of social desirability and agreeability on social media. Overall, New Zealand is a country that is well acknowledged and praised for its positive human rights records, yet it is not entirely free from social inequality including discrimination based on ethnicity and structural inequality. ${ }^{39}$ Another female participant commented that she would not post on the elections in New Zealand on social media because she finds New Zealand elections uninteresting, or in her own words, "boring." In her comment, she obliquely criticised New Zealand political culture and its current political apathy and made positive implications for the Sri Lankans' behavioural disposition towards the political affairs of their own country. Since the 1960 s New Zealand has experienced a steady decline in electoral participation. ${ }^{40}$ For instance, voter turnout in the 2011 New Zealand general election was a record low at 74.2 per cent, compared to the 2008 general election, where it stood at nearly 80 per cent. ${ }^{41}$

The participants therefore simultaneously made statements about their belongingness to Sri Lanka. On social media many of them closely followed Sri Lanka's recent election and its aftermath, and described it as a "good one," referring to both the minimal levels of election and post-election violence that resulted from it (in a context where Sri Lankan elections have a history of violence, abuse of state resources, and other violations of election laws), and the regime change it brought about, widely desired by many Sri Lankans. Some participants reported posting articles on the election that drew positive attention to Sri Lanka, according to them a country that is infamous in the eyes of the international community due to its longdrawn-out unstable and unsafe political climate, which they identified as having played a role in their parents' decision to leave Sri Lanka and settle in New Zealand. On social media therefore the participants attempted to salvage the Sri Lankan part of their identity - their ethnic origin - from the social stigma attached to it. As Moya ${ }^{42}$ in her collaborative work addressing criticism directed against the concept of identity contends, the participants attempted to reevaluate and rescue their identity of ethnic origin from the disrepute into which it has fallen. Further, for example in post (2) above, Sri Lanka was preceded by a hashtag or pound sign (\#Sri Lanka) turning Sri Lanka into a searchable item. On social media the hashtag/pound sign is used to draw attention and to promote: placing hashtag/pound sign in front of a word or phrase immediately turns the word/phrase into a searchable item by clicking on the sign. Therefore, by placing a hashtag in front of Sri Lanka, the participant made a conscious attempt to promote and propagate Sri Lanka and its peoples, even as she defined them as "Other" to her in the process. Likewise, the same participant, when she felt her identity was threatened, challenged or undermined in the dominant society, fell back on her ethnic group identity, as in post (3) above, and sought security and reaffirmation of self by expressing attachment to her 
ethnic origin. It was a strategy that she saw as being able to reduce the insecurity she felt in identifying with the host society.

This, on the one hand, showed the participants' ethnic consciousness, as Subervi-Velez ${ }^{43}$ recognizes "a consciousness of a kind," and on the other hand, conflicting cultural loyalties, where they straddle a binary construction of "us" and "them," the society of origin and host society, belonging to both and to neither. Therefore, through textual posts the participants continued to construct and reconstruct "us-them" polarization, their respective "Other" and thereby themselves, which was both situational and context-dependent. As Spivak in her controversial work, Can the Subaltern Speak? points out, "there is no true or pure other. Instead, the other always already exists in relation to the discourse that would name it as other." 44 Likewise, identity is not only how we present ourselves to others, but it is also part of being seen by others, as in the experience referred to in post (3) above. Identity is constructed prior to our actions (expressive as against performative) ${ }^{45}$ in particular settings where "location plays a more dynamic and active role in meaning making." 46 Mohanram in her acclaimed work, The Black Body, which converges various takes on identity (or body) in postcoloniality, recognises the shifting experiences of identity (or blackness) in relation to nation-space, from Algeria to the Antipodes, with emphasis on the particularities of space. Yet for all its meaning in racial identity, space has been overlooked and discounted in postcolonial theory. ${ }^{47}$ In identity performances, location is as important as the performer and the audience themselves. In this regard, the participants' construction as Other (or black) in Aotearoa was a shifting element of their self-identity, not static, which was likely to be reconstructed in different national and/or geographical settings; different stories will be narrated in different settings. Thus, extending the work of Spivak, it can be said that of the participants, as a diasporic community, that their 'Otherness' in the host society-Aotearoa-was defined not only by the historical or colonialist notions of identity where "ethnicity" sits as a particular artefact of colonization, but also by geographical elements, where their blackness in Aotearoa is caught in a dual relationship with White and minority. Hamel notes that "identity [is] ... a self-conscious and ongoing narrative ... constructed with others, in which individuals negotiate new subject positions in an often conflictive process, at the cross-roads of past, present and future."48 Therefore, identity is a product of a mix of social, political, historical and geographical processes that continue to reshape and redefine it across time and space.

Participants selectively listed themselves as members of multiple social groups, most of which were offline-based online groups. These groups ranged from youth and student associations, to friendship circles to fan pages, through which they tended to claim varying identities. All the participants identified themselves as members of one or more social groups founded upon ethnic origin. In these groups they were involved in promoting culture of origin among young Sri Lankans living in New Zealand through cultural and social events and gatherings, which can be seen as acts of ethnic revival. These groups functioned as a platform on which they connected with co-culturals in both virtual and physical spaces. They formed an important part of their social and cultural identity, in line with what Van Oudenhoven et al. note concerning cultural similarity: that it is particularly rewarding because it confirms that our beliefs and values are correct, thereby helping us to ease insecurity in interpersonal and intergroup relations. Social identification is an important cause of ethnocentrism that may manifest itself through ingroup favouritism. ${ }^{49}$

For many participants, both male and female, the sport of cricket played a central part in their virtual cultural identity. Cricket is the most popular sport in Sri Lanka. Following the 1996 Cricket World Cup triumph of the Sri Lankan national cricket team, the sport is probably the most watched event in the country today. Cricket and nationalism are strongly interconnected in Sri Lanka. "When the Sri Lankan team is playing, be it a test match or a oneday international, much of the country shuts down or at least pauses, as nearly everyone 
watches the match on the television or listens to it on the radio."50 These participants identified themselves with cricket in some way on social media. They listed themselves with big-name Sri Lankan national cricket players' online fan pages and actively followed their posts and updates online. They also posted and updated on cricket, primarily on Sri Lankan cricket, such as cricket matches and other cricket-related events, and played cricket themselves, for example for cricket clubs in Wellington. The following was shared by a participant, an 18 year old male born in New Zealand, in this regard:

I'm like an avid cricket fan. So, sometimes when I'm busy I can't watch a game and I catch up on social media. I follow a few pages on cricket, so they give score updates, highlights. So, it's much faster than going onto that website and finding out.

With most of my Sri Lankan friends who were also born here, we bond over things like Sri Lankan cricket, so we have things in common. Cricket is closely related to Sri Lanka. ${ }^{51}$

The next is from another interview with a 23 year old male who has been living in New Zealand for nearly 19 years: "Cricket is what I've always played. Softball is what I've always played. I would follow that more than rugby. I am a fan of big name players like Sangakkara, Dilshan. I just follow and see their posts." ${ }^{52}$ And this lastwas extracted from my interview with the 26 year old female participant quoted above: "On Tumblr, I say I'm a Lankan-Kiwi.... But I get patriotic about Sri Lanka like when it's the cricket, Sri Lankan patriotism." 53

Therefore, whether the participants were born in New Zealand or arrived and settled in New Zealand in their childhood, and though all were citizens of New Zealand, they implicitly identified themselves with Sri Lanka through their explicit attachment to cricket and the Sri Lankan national cricket team. None of them expressed similar interest in or enthusiasm for the sport of rugby. As a sport, rugby carries a powerful expression of New Zealand nationalism and identity, and has done since the early twentieth century. Ricketts in his work on New Zealand sports recognizes the status of rugby in "Rugbyland." He notes that rugby has become modern New Zealand's unofficial religion and no other sport has been able to challenge the status of rugby in New Zealand society and no other sport has been so exhaustively agonized over by the peoples of New Zealand. ${ }^{54}$

In the context of this study, cricket has been more than a game. It has become something "Other," a political affair that has been "transported from the comparatively contained and chaste theatre of the "sporting event," 55 through which the spectator re-negotiates and re-enacts the nation state and nationalistic sentiments. In this political theatre, for the participants, the spectators who are both inside and outside the space of the nation, the spectators who are produced through migration whose "blackness" marked a salient point of difference as immigrants, as the "Other," in mainstream New Zealand, were seemingly left little room to make choices of sports or to take sides about cricket, when the Sri Lankan national team was playing, but be subjects of the nation state. ${ }^{56}$ Interestingly, the participants supported the New Zealand national cricket team only when they were not up against the Sri Lankan national cricket team, when their identification with Sri Lanka or New Zealand, in the context of cricket, depended on the identity of the "Others." ${ }^{57}$ Hence, as Perera notes, everyday politics had plunged them into cricket long before they were aware of it ${ }^{58}$; in deciding between cricket and rugby in Rugbyland, cricket was what the participants could consciously relate themselves to and identify with. For them, cricket, apart from being a classic and clamorous entertainment, functioned as a channel through which ethnic and cultural differences could be contemplated and re-constructed. Hence, the sport of cricket, once a salient marker of Englishness, has become increasingly ethnicized and correspondingly perceived as "a [racialized] response to the realities of the present: "where you're at." 
and unity among the participants transcending the usual domain of entertainment to embody ethnic/cultural identity. ${ }^{60}$ On social media the participants, therefore, interpreted and defined one another's behaviour and it was these interpretations and definitions that formed the social bond between and among them that was reflected and embodied in a shared cultural identity.

To some extent, Buddhism also played a part in their cultural identity on social media. Buddhism is the major religion in Sri Lanka, followed predominantly by the Sinhalese, where religious narrative and myth, symbolism and ritual have been paramount in the formation of non-Western modern national identity and nationalist movements in Sri Lanka. ${ }^{61}$ Some participants listed themselves as members of Buddhist religious groups that were organized around religious education via activities such as posting religious talks and articles online and organizing religious events and gatherings, both online and offline. However, it was interesting to note that the participants' involvement with these groups was not as active as their involvement with other social and cultural groups, such as youth associations or friendship circles, and thus represented a comparatively peripheral or secondary cultural identity.

Participants also listed themselves with Kiwi-based social groups on social media through which they expressed their belonging to a "Kiwi identity." Specifically, in terms of musical and performative aesthetic and attachment, they joined lists that affiliated them primarily with Western (i.e., American and/or European) collectives and individuals, such as Western recording artists and bands, TV shows and movies - the popular genres and icons of modern Western societies. The musical and performative landscape of modern New Zealand is heavily influenced by Western popular culture, especially American. As Lealand points out, American popular culture has for many years been imported to New Zealand, in the shape of films, popular music, television programmes, and fast food franchises, such that its presence is both persistent and consistent and makes a significant part of Kiwi popular culture. ${ }^{62}$ Likewise, Melnick and Jackson contend that New Zealand, as a country with a small population, is forced to be heavily dependent on imported media programming, most of which is currently from America, Britain and Australia. They further note that as a former British colony, New Zealand's lack of "natural filters" (such as language) make it less possible to resist foreign influences, especially American. As a result, the music, movie and television consumption patterns of New Zealand youth are heavily influenced by American (Western) popular culture to the extent that the presence of popular American cultural icons (e.g., Michael Jackson, Arnold Schwarzenegger, Jim Morrison) extend well beyond simple admiration to include impacts on beliefs, values, self-appraisals, and behaviors. ${ }^{63}$

Clearly, as members of an ethnic minority community who've been living in New Zealand their entire or most of their young lives, the participants' consumption patterns were largely influenced and shaped by the popular Western cultural acts and trends, which can be seen in their choices of Western entertainment. Their life-long exposure to and contact with Western culture has both inevitably and invariably developed in themselves a strong taste of Western entertainment. Hence, in terms of musical and performative aesthetic, the participants clearly identified themselves with popular Western culture and displayed an apparent detachment from that of their culture of origin. Apparently, their lack of effective communication skills and ability in native language - Sinhala - hampered them in making any meaningful and gratifying connection with Sinhala musical and performative aesthetics. Yet more importantly, it was likely that the participants' identification with that part of Kiwi culture played a part in their effort to fit into New Zealand society and facilitated and eased their pressures on assimilation; such acts of identification served as "outward symbols of assimilation" 64 to New Zealand society, through which the participants attempted to negotiate a place in their adopted homeland. As Viswanath and Arora explain, immigrants' success in a host society depends on their degree of assimilation and learning the ropes of the system. ${ }^{65} \mathrm{In}$ this regard, Western musical and performative aesthetic offer the participants more attractive 
and populist means of identity formation and representation and thereby effective connection with the surrounding White-Kiwi-mainstream culture, where both tastes and cultural consumption are central in defining commonality or a common identity. ${ }^{66}$

Hence, of the two cultures, the participants picked and "appropriated (i.e., to make one's own)" ${ }^{\prime 67}$ differing elements for emulation, through which they [re]negotiated and projected both individual and collective identities. In doing so, they apparently tried to distinguish and distance themselves from their idea of "average" Sri Lankan youth: as Cutler contends, the drive for immigrant groups to distance and detach themselves from blackness and position themselves by using the discourse of White mainstream culture is historically rooted and seemingly natural given the political, social, cultural and economic dominance of Whites in immigrant destinations. ${ }^{68}$

\section{Discussion and Conclusion}

In the context of this study, social media enabled the participants to relate closely to the host society as well as maintaining their relations with the society of origin. At the same time, they could lose contact with whichever group they felt not closely related to. On social media they made both implicit and explicit statements of identity, that is, as well as straightforward statements of identity, they made identity claims through their visual and textual posts, and selective affiliation with individuals and social groups. Interestingly, as part of the ongoing flow of social interaction and communication, their identities were "shown rather than told" 9 on these virtual social spaces, through which identity performances were elevated to a novel level.

Participants' acculturation has been seen to consist of one main strategy: integrated identity. They retained, consciously or unconsciously, a strong ethnic identity while also identifying with the host society, thus negotiating and renegotiating bicultural identities online. External trappings of the host culture dominated their performances ${ }^{70}$ such as fluency in English language and an explicit preference for Western musical and performative aesthetic, yet they simultaneously identified themselves with the nation of origin, Sri Lanka. Participants carefully selected aspects of their culture of origin, concurrently confirming and contradicting its normative ways and expectations. As one female participant commented, "[I] have used both worlds. I try to take the good of both sides." This means they have given up some elements of their cultural heritage without completely relinquishing their cultural identity, ${ }^{71}$ thus displaying a "selective assimilation" to the host society. Social media therefore enabled the participants to both retain and break their original links and associations, ${ }^{72}$ and experience a sense of empowerment through identity, where they combined and appropriated, symbolically, the two spaces and constructed a new-integrated-identity. This process is called "ethnogenesis": the creation of new identity borders that emerge from the experience of certain shared social and juridical conditions based on pre-existing factors such as skin colour and language. ${ }^{73}$ In the process, the participants crossed the borders of both the native land (Sri Lanka) and host land (New Zealand), alternating their self-identities and feelings of belongingness between the two spaces depending on the situation. Their distinction between "home" [us] and "host" [them] was therefore circumstantial and dubious and was not marked by "hot loyalties or thick commitments." 74

Interestingly, their integrated identity was expressed in terms of a hyphenated identity referring to themselves as "Sri Lankan-Kiwi," not necessarily "Kiwi-Sri Lankan." This hyphenated identity was founded upon their context of socialization. As transnational youth, their primary socialization has taken place within the cross-currents of bicultural fields. ${ }^{75}$ As Boekestijn points out, referring to the role of social networks in the adaptation and assimilation of Dutch immigrants to Canadian society, in the context of this study, social media played the function of cultural rehearsal and expression: on social media the participants received 
emotional support (feeling liked), evaluative support (feeling respected), instrumental support (feeling helped), and presence support (feeling another's support), ${ }^{76}$ all of which were associated and connected primarily with their co-culturals. Social media was a performative space, which was exuberant, yet one in which the participants simultaneously engaged in meaningful discourse and dialogue as well as emotional bond maintenance. ${ }^{77}$ Social media created new imagined selves and imagined communities, that we can call "communities of sentiments."78 These sodalities operated beyond more narrowly defined conditions of identity production and boundaries of the nation, and were replaced by new expressions, imaginings, and conceptions of transnational identities. Extending Benedict Anderson's concept of "imagined communities" to twentieth- and twenty-first-century electronic mass media, Appadurai further recognizes that these imagined selves and imagined worlds are neither purely emancipatory nor entirely disciplined. ${ }^{79}$

For the participants, identity portrayed on social media was skewed ${ }^{80}$ : social media displayed only a snapshot ${ }^{81}$ of the self, in which only the best or the most desirable aspects of the self were portrayed. The self is an integral part of the interface between physical body and the dynamic social system, ${ }^{82}$ and on social media the participants [re]produced different versions of the self: "a more or less person," ${ }^{83}$ portraying "the self as an emergent project as well as the very creative subject and object of that process." 84 Virtual identities were played out and therefore remained neither fixed nor singular and shifted and changed depending on the situation; self-identity was accelerating and ambiguous. Through information mediation and control, the participants projected a self that sought agreement from and with their online audience in a manner that could facilitate and promote social interaction and group cohesion, while their online audiences were diverse, and so their projection of self for each audience was likewise distinct. Hence, the "definition of the situation" was certainly of consequence to the participants' identity performances on social media and 'there ... [was] no 'true self' hidden in some magical realm." ${ }^{85}$ Rather, self was enacted and re-enacted depending on the moment.

The participants, in their roles as both virtual performers and onlookers (or "lurkers"), built their online identities out of the subjective meanings they imposed on behaviours, events, symbols, and objects (i.e., the performative actions, behaviours and gestures through which identity is produced; according to Butler, the manifestations through which the notion of performativity is constructed ${ }^{86}$ ) on social media. The meanings of these identity signifiers, that is to say, were socially constructed through interpretation. For the participants, social media served as a democratizing instrument, "a kind of virtual laboratory for exploring and experimenting with different versions of self," 87 where each version was invented and reinvented through social interaction, ${ }^{88}$ and thus subjective, as a personal claim to individuality. Virtual identities performed on social media thus defied the essentialist or foundationalist notion of identity where identity is considered to be something deep, abiding and foundational, turning it into something superficial, fleeting and contingent ${ }^{89}$; the participants, as a diasporic community, were dynamically [re]creating identities, both individual and collective, that transcended the nationalist reach of the nation through the claiming of new categories of identification. ${ }^{90}$ As one female participant aptly articulated in my personal interview with her: "This [Zealand] is where my home is. Sri Lanka would be my motherland." The participants ruminated nostalgically on their imagined homelands and communities, on their past, and simultaneously created new and alternative homelands, communities and belongingnesses through virtual social spaces. 


\section{Acknowledgement}

This research study was undertaken during my term of residency at the Stout Research Centre for New Zealand Studies, Victoria University of Wellington. I am sincerely thankful to Professor Lydia Wevers, Director of the Stout Research Centre for New Zealand Studies and Professor Brigitte Bönisch-Brednich, Head, School of Social and Cultural Studies, Victoria University of Wellington, for all the support given to me. I would like to thank both reviewers and the copyeditor of the journal for their insightful and helpful comments, which greatly improved my paper. Also, I am thankful to the Editor of the journal, Associate Professor Anna Green, for all the assistance extended to me in publishing this paper. Furthermore, I wish to acknowledge the time and effort of the research participants. Their willingness to participate in my study enabled me to learn a great deal from them, for which I am truly grateful. My special thanks go to the young Wellingtonian who put me in touch with many research participants, which made my work so much easier. Last but not least, my special thanks also go to Sarah Gaitanos and Debbie Levy at the Stout Research Centre.

${ }^{1}$ J. Wilson, "Story: History," Te Ara, The Encyclopedia of New Zealand, accessed 11 October, 2015, http://www.teara.govt.nz/en/history.

${ }^{2}$ C. Ward and A. Masgoret, "Attitudes towards Immigrants, Immigration, and Multiculturalism in New Zealand: A Social Psychological Analysis," International Migration Review 42, no. 1 (2008): 228.

3 “2013 Census Totals by Topic - Tables," Statistics New Zealand, accessed 18 May, 2015, http://www.stats.govt.nz/Census/2013-census/data-tables/total-by-topic.aspx; E. Pio, "Knotted strands: Working lives of Indian women migrants in New Zealand," Human Relations 58, no. 10 (2005): 1278.

${ }^{4}$ K. Viswanath and P. Arora, "Ethnic Media in the United States: An Essay on Their Role in Integration, Assimilation, and Social Control," Mass Communication \& Society 3, no. 1 (2000): 39.

5 "Sri Lankans," Te Ara, The Encyclopedia of New Zealand, accessed 18 February 2015, http://www.teara.govt.nz/en/search/teara?keys=sri+lankans.

${ }^{6}$ N. Elias and D. Lemish, "Media Uses in Immigrant Families: Torn between 'Inward' and 'Outward' Paths of Integration," The International Communication Gazette 70, no. 1 (2008): 21.

${ }^{7}$ S. Hamel, “If I'm Like Them, They Will Accept Me More': How New Zealand Immigrants Negotiate and Perform Gendered Social Identities," Journal of New Zealand Studies 8 (2009): 145.

${ }^{8}$ N. Elias and D. Lemish, "Media Uses in Immigrant Families: Torn between 'Inward' and 'Outward' Paths of Integration," The International Communication Gazette 70, no. 1 (2008): 21-40.

${ }^{9}$ P. M. L Moya, "Introduction: Reclaiming Identity," in Reclaiming Identity: Realist Theory and the Predicament of Postmodernism, ed. P. M. L. Moya and M. R. Hames-Garcia (Hyderabad: Orient Longman Private, 2001), 22.

${ }^{10}$ G. Youngs, "Cyberspace: The New Feminist Frontier?" in Women and Media: International Perspectives, ed. K. Ross and C. M. Byerly (Oxford: Blackwell Publishing, 2006), 188.

${ }^{11}$ E. Pio, "Knotted Strands: Working Lives of Indian Women Migrants in New Zealand," Human Relations 58, no. 10 (2005): 1282.

${ }^{12}$ N. K. Denzin and Y. S. Lincoln, "Introduction: The discipline and practice of qualitative research," in Handbook of Qualitative Research, ed. N. K. Denzin and Y. S. Lincoln (Thousand Oaks, CA: Sage, 2000), 6; cited in E. Pio, "Knotted Strands," 1282.

${ }^{13}$ R. King and A. Christou, "Cultural Geographies of Counter-Diasporic Migration: The Second Generation Returns 'Home," accessed 12 October, 2015,

https://www.sussex.ac.uk/webteam/gateway/file.php?name=mwp45.pdf\&site=252 .

${ }^{14}$ See E. Pio, "Knotted Strands," 1283. 
${ }^{15}$ S. Zhao, S. Grasmuck, and J. Martin, "Identity Construction on Facebook: Digital Empowerment in Anchored Relationships," Computers in Human Behaviour 24 (2008): 1823.

${ }^{16}$ L. Benaquisto, "Codes and Coding," The SAGE Encyclopedia of Qualitative Research Methods, ed. in L. M. Given (Thousand Oaks, CA: SAGE, 2008), 86-89.

${ }^{17}$ S. Zhao, S. Grasmuck, and J. Martin, "Identity Construction on Facebook": 1817.

${ }^{18}$ J. A. Bargh, K. Y. A. McKenna and G. M. Fitzsimons, "Can You See the Real Me? Activation and Expression of the "True Self' on the Internet," Journal of Social Issues 58, no. 1 (2002): 35.

${ }^{19}$ See A. Reed II, M. R. Forehand, S. Puntoni, and L. Warlop, "Identity-Based Consumer Behaviour," International Journal of Research in Marketing 29, no. 4 (2012): 318.

${ }^{20}$ S. Zhao, S. Grasmuck, and J. Martin, "Identity Construction on Facebook": 1817.

${ }^{21}$ Ibid., 1818.

${ }^{22}$ G. T. Marx, "What's in a Name? Some Reflections on the Sociology of Anonymity," The

Information Society: An International Journal 15, no. 2 (1999): 99-112; S. Zhao, S. Grasmuck, and J. Martin, "Identity Construction on Facebook": 1816-36.

${ }^{23}$ C. Morrill and D. A. Snow, "The Study of Personal Relationships in Public Spaces," in Together

Alone: Personal Relationships in Public Places, ed. C. Morrill, D. A. Snow, and C. H. White

(Oakland, CA: University of California Press, 2005), 18.

${ }^{24}$ S. Zhao, S. Grasmuck, and J. Martin, "Identity Construction on Facebook": 1826.

${ }^{25}$ Ibid., 1820.

${ }^{26}$ See E. Pearson, “All the World Wide Web's a Stage: The Performance of Identity in Online Social

Networks," First Monday 14, no. 3 (2009), accessed 8 October, 2015,

http://firstmonday.org/ojs/index.php/fm/article/view/2162/2127.

${ }^{27}$ H. Ferguson, Religious Transformation in Western Society (Routledge Revivals): The End of

Happiness (London: Routledge, 1992), 23.

${ }^{28}$ Y. Uchida and Y. Ogihara, "Personal or interpersonal construal of happiness: A cultural psychological perspective," International Journal of Wellbeing 2(4): 354-356.

${ }^{29}$ See G. Duncan, "After happiness," Journal of Political Ideologies 12(1) (2007): 86; Y. Uchida and Y. Ogihara, "Personal or interpersonal construal of happiness: A cultural psychological perspective," International Journal of Wellbeing 2(4): 356.

${ }^{30}$ See E. Pearson, "All the World Wide Web's a Stage."

${ }^{31}$ Ibid.

${ }^{32}$ Personal Interview, 19 February, 2015.

${ }^{33}$ S. Y. Evans, "Book Review: Black Body: Women, Colonialism, and Space," Journal of

International Women's Studies 6, no. 2 (2005): 173.

${ }^{34}$ E. Pio, "Knotted Strands," 1279.

${ }^{35}$ Author's virtual ethnography.

${ }^{36}$ Personal interview, 31 December, 2014.

${ }^{37}$ Personal interview, 26 January, 2015 (Emphasis added).

${ }^{38}$ B. Hwang and Z. He, "Media Uses and Acculturation Among Chinese Immigrants in the USA: A

Uses and Gratifications Approach," International Communication Gazette 61, no. 5 (1996): 7.

${ }^{39}$ See R. Harris, M. Tobias, M. Jeffreys, K. Waldegrave, S. Karlsen, and J. Nazroo, "Racism and

Health: The Relationship Between Experience of Racial Discrimination and Health in New Zealand," Social Science \& Medicine 63, no. 6 (September 2006): 1428.

${ }^{40}$ See "Story: Elections and campaigns, Page 4-Voter participation and turnout," Te Ara, The

Encyclopedia of New Zealand, accessed 14 October, 2015, http://www.teara.govt.nz/en/elections-andcampaigns/page-4.

${ }^{41}$ See "NZ social indicators: Voter turnout," Statistics New Zealand, accessed 14 October, 2015, http://www.stats.govt.nz/browse_for_stats/snapshots-of-nz/nz-social-

indicators/Home/Trust\%20and\%20participation\%20in\%20government/voter-turnout.aspx.

${ }^{42}$ P. M. L Moya, "Introduction: Reclaiming Identity," 2.

${ }^{43}$ F. A. Subervi-Velez, "The Mass Media and Ethnic Assimilation and Pluralism: A Review and

Research Proposal with Special Focus on Hispanics." Communication Research 13 (1986): 73. 
${ }^{44}$ G. C. Spivak. 1988. Can the Subaltern Speak? Summary, accessed October 10, 2014, http://www.uky.edu/ tmute2/geography_methods/readingPDFs/spivak.pdf. [NEEDS A DIFFERENT CITATION]

${ }^{45}$ See R. Hague, Autonomy and Identity: The Politics of Who We Are (Abingdon: Routledge, 2011), 3.

${ }^{46}$ S. Y. Evans, "Book Review," 172.

${ }^{47}$ See R. Mohanram, Black Body: Women, Colonialism, and Space (University of Minnesota Press: Minneapolis, 1999).

${ }^{48}$ S. Hamel, "'If I'm Like Them,"” 147.

${ }^{49}$ J. P. Van Oudenhoven, C. Ward, and A. Masgoret, "Patterns of Relations Between Immigrants and Host Societies," International Journal of Intercultural Relations 30 (2006): 643-44.

${ }^{50}$ D. Bass, Everyday Ethnicity in Sri Lanka: Up-country Tamil identity politics (Abingdon: Routledge, 2013), 90.

${ }^{51}$ Personal interview, 24 February, 2015.

${ }^{52}$ Personal interview, 27 February, 2015.

${ }^{53}$ Personal interview, 26 January, 2015.

${ }^{54}$ H. Ricketts, The Awa Book of NZ Sports Writing (Wellington: Awa Press, 2010).

${ }^{55}$ S. Perera, "'Cricket, with a Plot': Nationalism, Cricket and Diasporic Identities," Journal of Australian Studies 65 (2000): 17.

${ }^{56}$ Ibid., 16.

${ }^{57}$ See G. Bailey and J. Peoples, Essentials of Cultural Anthropology (Belmont, CA: Wadsworth Publishing, 2013), 215.

${ }^{58}$ S. Perera, "“Cricket, with a Plot,"” 16.

${ }^{59}$ Ibid., 26

${ }^{60}$ See N. Nair, "Cricket Obsession in India: Through the Lens of Identity Theory," Sport in Society: Cultures, Commerce, Media, Politics 14, no. 5 (2011): 569-80.

${ }^{61}$ R. Friedland, "Religious Nationalism and the Problem of Collective Representation," Annual Review of Sociology 27 (2001): 129.

${ }^{62}$ G. Lealand, A Foreign Egg in Our Nest? American Popular Culture in New Zealand (Wellington: Victoria University Press, 1988), 13-14.

${ }^{63}$ M. J. Melnick and S. J. Jackson, "Globalization American-Style and Reference Idol Selection: The Importance of Athlete Celebrity Others among New Zealand Youth," International Review for the Sociology of Sport 37, no. 3-4 (2002): 429-44.

${ }^{64} \mathrm{~K}$. Viswanath and P. Arora, "Ethnic Media in the United States: An Essay on Their Role in Integration, Assimilation, and Social Control," Mass Communication \& Society 3, no. 1 (2000): 50. ${ }^{65}$ Ibid.

${ }^{66}$ See A. Christin, "Omnivores versus snobs? Musical tastes in the United States and France," Princeton University Center for Arts and Cultural Policy Studies, Working Paper 40, Summer 2010, accessed October 8, 2015, http://www.princeton.edu/culturalpolicy/workpap/WP40-Christin.pdf.

${ }^{67}$ J. Clifford, The Predicament of Culture: Twentieth-Century Ethnography, Literature, and Art (London: Harvard University Press, 1988), 221.

${ }^{68}$ C. Cutler, "Brooklyn style: Hip-Hop Markers and Racial Affiliation Among European Immigrants in New York City," International Journal of Bilingualism 12, no. 1-2 (2008): 9.

${ }^{69}$ S. Zhao, S. Grasmuck, and J. Martin, "Identity construction on Facebook," 1816.

${ }^{70}$ J. P. Van Oudenhoven, C. Ward, and A. Masgoret, "Patterns of Relations," 647.

${ }^{71}$ Ibid.

${ }^{72}$ N. Elias and D. Lemish, "Media Uses in Immigrant Families: Torn between 'Inward' and 'Outward' Paths of Integration," The International Communication Gazette 70, no. 1 (2008): 23.

${ }^{73}$ C. Feixa, O. Romani, N. Hakim, A. L. Reolon, L. Porzio, and A. Rodriguez, "Spain: Irregular Lives in the Southern Rim of Europe," in Inclusion and Exclusion of Young Adult Migrants in Europe:

Barriers and Bridges, ed. K. Fangen, K. Fossan and F. A. Mohn (Farnham: Ashgate, 2010), 40.

${ }^{74}$ B. S. Turner, "The Possibility of Primitiveness: Towards a Sociology of Body Marks in Cool Societies," Body \& Society 5, no. 2-3 (1999): 39.

${ }^{75}$ S. Vertovec, "Conceiving and Researching Transnationalism," Ethnic and Racial Studies 22, no. 2 (1999): 451. 
${ }^{76}$ C. Boekestijn, "Intercultural Migration and the Development of Personal Identity: The Dilemma Between Identity Maintenance and Cultural Adaptation," International Journal of Intercultural Relations 12 (1988): 90-91.

${ }^{77}$ See E. Pearson, "All the World Wide Web's a Stage."

${ }^{78}$ A. Appadurai, Modernity at Large: Cultural Dimensions of Globalization (Minneapolis: University of Minnesota Press, 1996), 8; cited in N. Constable, Romance on a Global Stage: Pen Pals, Virtual Ethnography, and "Mail Order" Marriages (Oakland: University of California Press, 2003), 32. ${ }^{79}$ Ibid.

${ }^{80} \mathrm{I}$ have to thank one participant for making this point during my in-person interview with him.

${ }^{81}$ Pointed out by the same participant.

${ }^{82}$ R. F. Baumeister, "The Self," in Advanced Social Psychology: The State of the Science, ed. R. F. Baumeister and E. J. Finkel (New York: Oxford University Press, 2010), 139.

${ }^{83}$ P. Vannini and J. P. Williams, "Authenticity in Culture, Self, and Society," in Authenticity in Culture, Self, and Society, ed. P. Vannini and J. P. Williams (Farnham: Ashgate, 2009), 4.

${ }^{84}$ Ibid.

${ }^{85}$ R. F. Baumeister, "The Self," 139.

${ }^{86}$ See J. Butler, Gender Trouble: Feminism and Subversion of Identity (New York: Routledge, 1990).

${ }^{87}$ J. A. Bargh, K. Y. A. McKenna and G. M. Fitzsimons, "Can You See the Real Me?" 33.

${ }^{88}$ P.Vannini and A. Franzese, "The Authenticity of Self," 1623.

${ }^{89}$ E. Sevänen, "From Modernity and Postmodernity to Globalization," in Cultural Identity in

Transition: Contemporary Conditions, Practices and Politics of a Global Phenomenon, ed. : J.

Kupiainen, E. Sevänen, and J. A. Stotesbury (Delhi: Nice Printing Press, 2004), 10.

${ }^{90}$ See S. Perera, “'Cricket, with a plot,"” 25. 